\title{
Gendered patterns in music mediation: a study of male and female performers at the Øya festival using multiple data sources
}

\author{
Anne Danielsen ${ }^{\mathrm{a}}$, Yngvar Kjus ${ }^{\mathrm{a}}$, and Emil Kraugerud ${ }^{\mathrm{a}}$ \\ aDept. of Musicology, University of Oslo \\ Box 1017 Blindern \\ NO-0315 Oslo, Norway
}

\begin{abstract}
Despite a growing awareness of gender bias in the music sector, there is a lack of research into the particular ways in which this imbalance manifests itself in contemporary music culture. This article combines data from editorial and new user-controlled media to investigate gender patterns in music conveyance, in conjunction with the Øya festival in Norway. It finds that the traditional male dominance in editorial media (music journalism and radio playlists) is both confirmed and denied on user-controlled media (social media and streaming services). While generally favouring male artists, the usercontrolled media were especially positive for the female festival artists after the festival concert. This finding indicates that the direct meeting of artists and audience at the festival is particularly favourable to female artists. Moreover, the study's results show that probing the intersection between music performance (experience) and mediated discourse about music (exposure) is key to understanding the potential reach of female artists in the digital era.
\end{abstract}

Keywords: music festival; gender; streaming; social media; editorial media; radio 


\section{Introduction}

It is challenging for any artist to connect with an audience, but it is perhaps particularly so for women: research has demonstrated that music journalism, radio playlists and various other established music intermediaries are consistently male dominated. The 2000s have, however, seen the rise of new digital media that are now overseen by artists and fans themselves, including social media platforms and streaming services. Does this growing use of new media simply fortify existing gender patterns, or does it supply novel opportunities for engagement to female musicians and their potential audiences? We set out to answer this question by looking at music mediation in conjunction with a music festival, as festivals are occasions marked by considerable efforts to showcase artists and develop new fan relationships. Our empirical starting point is the music mediation surrounding the Øya festival, which is the largest popular-music festival in Norway. It annually features roughly eighty artists, ranging from international headliners to local acts, and attracts about forty thousand visitors. This study will assess, in particular, how male and female artists were conveyed via new user-controlled media (Twitter and the music streaming service WiMP) in relation to their coverage by established editorial media.

\subsection{Editorial and user-controlled music mediation}

It is widely acknowledged that the music business is male dominated, from its record labels and production studios (Reddington, 2007) to its media of distribution (McLeod, 2002). Once female artists have created their music, then, they face the next (and perhaps graver) challenge of reaching out with it via channels with a male bias, including journalistic outlets, radio playlists, record stores and live arenas (Rashaun, 2004; Schmutz, 2009; Kjus, 2016). According to Leonard (2007), this part of the music industry performs key intermediary functions through the 'selection of interesting new releases' and the 'interpretation of those records to their readers' (p. 65, original emphasis). They thereby exert a form of gatekeeping power which is well recognised in news studies, one which, in the field of music, includes the ability to present and validate new artists, genres and tastes to the public (Hesmondhalgh, 2013). This power may in turn sustain the status quo with regard to gender balance. 
Gender bias is when gender systematically affects people's opportunities. It can take the form of performance expectations that 'subtly bias who speaks up and who holds back, how they evaluate each other's performance, who becomes influential, and who seems appropriate for leadership', according to Ridgeway (2011, p. 110). Studies indicate that gender imbalances are upheld by institutions and expressed through access (or non-access) to hierarchical structures, such as the limited coverage of female authors by elite newspapers (Berkers et al., 2016). While there is likely to be considerable variation between newspapers in this regard, online platforms provide opportunities which entirely circumvent traditional institutional frameworks and appear to pay attention to a broader range of authors, including female authors in particular (Verboord, 2011). In this way, new opportunities for interplay emerge between 'the established media and amateur voices outside of them' (Kristensen et al., 2017, p. 42), presenting a new opportunity for cultural critique which we will begin to unpack in what follows. We will do so by combining different data sources, including the relatively untapped digital data generated by social media and streaming services. We will assess the impact of an artist's gender on that artist's mediation in association with the Øya festival by relating it to other factors, such as an artist's overall popularity.

A shared trait of the traditional media is that they are editorial, meaning that the selection and presentation of music is controlled by media professionals. Editorial groups constitute social and economic organisations which develop relatively stable work patterns, though the stability varies with the traditions and size of the given organisation (Cottle, 2006). Editorial positions in music media have usually been filled by men. This is a legacy from the early days of music journalism (and media production in general) - the rock critics who published Rolling Stone and Creem in the 1960s, for example, were predominantly men (Lindberg et al., 2005). It is widely acknowledged that editorial groups develop norms and standards which provide direction and ensure efficiency in their work. Women who seek positions in such groups are also expected to adhere to the established ways of doing things. Editorial cultures can become conservative as a result, and they can even come to mirror the power structures of the areas which they cover.

In the 2000s, however, online and mobile media have offered opportunities beyond the established intermediaries - in particular, new means of discussing music, via social media, as well as listening to it, via downloading and streaming services. Already at the turn of the century, Jones (2002) noted that ' $[t]$ here is clearly a need for people to share music, whether they are musicians or fans (or both). The Internet and 
digital music have filled that need better than other technologies before them' (p. 230). New media have been viewed with optimism with regard to attracting an audience, as expressed by the Swedish artist Johan Angergård: 'With the Internet you get bands known, and that creates a market for them, both for live shows and selling albums' (Baym, 2011, p. 30). While new opportunities are clearly emerging, it remains to be established exactly how they work, how they are used, and what impact they have upon female artists and their audiences.

Traditionally, radio channels have performed a key role in broadcasting music, while newspaper and magazine journalists have provided various reviews and comments about music (Frith, 1983). Both these forms are highly curated. In contrast, the new media of the 2000s are characterised by the fact that they are not under editorial control. These media have been built upon the open infrastructure of the Internet, whose various arenas for social interaction and exchange have encompassed everything from IRC (Internet Relay Chat) channels to peer-to-peer networks for file sharing (Lüders, 2007). Although such platforms initially developed outside the control of commercial companies, large international corporations have increasingly engaged and invested in some of the services that are popular today, including Facebook, Twitter, YouTube and Spotify (Mjøs, 2012). Along the way, these services have developed editorial elements that govern the extent of user participation, as well as the conveyance of certain kinds of content (Kjus, 2016).

Despite these developments, the new media of interaction and exchange facilitate user control, both for self-expression and for individual content selection, at a different level from traditional media. Twitter, which in 2016 had more than 300 million users, is a free micro-blogging service which allows people to write messages potentially reaching others around the world, and which allows users to choose whom to follow (Larsson and Moe, 2014). Twitter foregrounds the potential for outreach and exposure, in that everything which is posted there is openly available for everyone, whereas Facebook encourages more bounded social interactions. Spotify, which in 2016 had more than 100 million users, is a streaming service which, in return for a monthly subscription fee or advertising exposure, gives access to a database of more than 30 million tracks, from which users can select and share music with one another (Hagen, 2015).

In sum, these media, and others like them, including YouTube and SoundCloud, provide artists with new arenas to convey their music (some command more followers than most newspapers) and audiences with new means of orienting themselves in the 
vast terrain of available music. Importantly, these new means are not only for receiving music but also for expressing feelings about it and promoting personal playlists.

Alongside editorial media, then, user-controlled media is on the rise, with the potential to introduce new patterns into the ongoing effort to gain attention, perhaps to the extent of undermining the male domination of traditional music mediation.

\subsection{Music mediation and festivals}

In principle, music can be conveyed by expressing opinions about it or by giving access to the work itself. Music and 'speech about music' (Feld, 1984) are, however, intrinsically connected - according to Feld, one does not exist without the other. When individual private experiences with a live music concert or a streaming service enter the public/social domain through editorial or user-controlled media, for example, they are transformed into 'speech about music'. However, the latter also influences the former: how we talk about music influences how we hear it. The relationship between music and speech about music can thus be described as a neverending dialectic of 'event' and 'meaning', or of experiences and the act of making meaning out of those experiences (Ricoeur, 1984; Danielsen, 2006).

In this article, we will study music mediation in a specific context that involves both of these aspects of conveyance: the music festival. Festivals are an important aspect of musical culture in the 2000s (Robinson, 2015) and have become key arenas for artists to perform before new (and old) fans, and for the audience to hear and share new music. This is a global phenomenon within which Norway is strongly represented: it is estimated that there are about one thousand cultural festivals annually in Norway, and that almost half of them are music festivals (Tjora, 2013). The trend has many driving forces, including international tourism and the economic incentive for performers of falling record sales (Tschmuck et al., 2013). In a globalised and competitive industry, big festivals also present an opportunity to stand out from the crowd. One reason why festivals stand out is because of their media coverage. While Woodstock is a classic example of a mediated festival, Roskilde, Coachella and Glastonbury annually give testimony to the intensive media traction of the music festival. Media coverage of the upcoming event attracts people to its live performances, and the reviews published afterwards can fuel interest in the performers' recordings. Editorial media also have more indirect effects on festivals. Their general coverage and replay of popular artists are likely to affect how festivals book and program artists, 
including decisions regarding remuneration, headliner status, stage size and play times. The selection and presentation of festival performers might in this way mirror the patterns of the editorial media, and festivals in Norway have, in fact, repeatedly been criticised for a low proportion of female performers. The largest festivals, such as Øya, have in turn become annual occasions of much debate (see, for example, Ramstad, 2010; Wisløff, 2014). Editorial media also constitute an arena for these critical views, which perhaps is one reason why the 2000s, in fact, have seen signs of change in the booking as well as the mediation of female artists (addressed further below).

New media have, however, provided even more direct routes for people's voices and experiences. Today, audiences (and artists) can increasingly broadcast their own expectations regarding upcoming performances; they can express their opinions about them and share playlists of their favourite (female or male) artists. The rise of usercontrolled media might thereby challenge, or at least represent a viable alternative to, editorial media in the promotion of and reporting from festivals.

In sum, then, a distinction can be made between discourse about artists, which contributes to their music's exposure, and access to their music, which enables its experience (listening). Media outlets such as radio and streaming, which (also) include the music as such, allow for an experience of music as an 'event', in the sense of Ricoeur - that is, music prior to (and after) the meanings and interpretations which constitute the discourse about it. Media such as newspapers or Twitter, on the other hand, deal with 'speech about music' and represent an exposure to music rather than an experience with music as such. In the present context, we are interested in both forms of music conveyance. We also want to investigate the ways in which audiences' direct experiences of music manifest in the form of evaluation in both editorial and usercontrolled media.

One reason to zoom in on a festival is the uniqueness of live performance as musical communication. In concerts, artists and audience meet one another face-toface - a powerful performance can ignite or strengthen interest in an artist and his/her/their recordings, whereas a poor one can extinguish it (Fonarow, 2006; Kjus \& Danielsen, 2014; Danielsen \& Kjus, 2017). The festival thus represents a potent site for audiences to make up their own minds about a performer, and, also, to share those impressions with others. Previous research has offered ethnographic accounts of how mobile media are actively used to reach out to peers during concerts (e.g., Bennett, 2014), though quantitative documentation and effect analyses remain scarce. 
The hypothesis underlying the present work is that the new, user-controlled media, in combination with the heightened value of experiencing music live at festivals, have the potential to disrupt gender hierarchies in music because they alter patterns of musical experience, exposure and evaluation. In what follows, we will compare how male and female festival performers were conveyed via editorial and user-controlled media in connection with a music festival. Our empirical starting point is the Øya festival, the largest music festival in Norway, which is covered and conveyed extensively via these kinds of media. The next section presents our empirical and methodological decisions, including the selection of media and how these will be examined and compared.

\section{Materials and methods}

\subsection{Selection of festival and media platforms}

Along with its size and media traction, Øya is also interesting because of its booking, its artists and its audiences. The Øya festival started in 1999 as the joint initiative of a handful of rock clubs in Oslo and featured exclusively local bands. Its artist booker (Claes Olsen) had a reputation for knowing about talented and upcoming artists, and as the festival grew, this awareness of musical trends extended to newer genres (including electronica, rap, metal and soul) and regions (particularly northern Europe and the United States). Øya is now a highly attractive arena for performers, featuring approximately eighty artists that draw about forty thousand visitors to the four-day event.

In terms of gender, Øya is representative of the aforementioned widespread industry bias but also reflects a tendency towards a higher representation of female artists, as the overview in figure 1 indicates. 


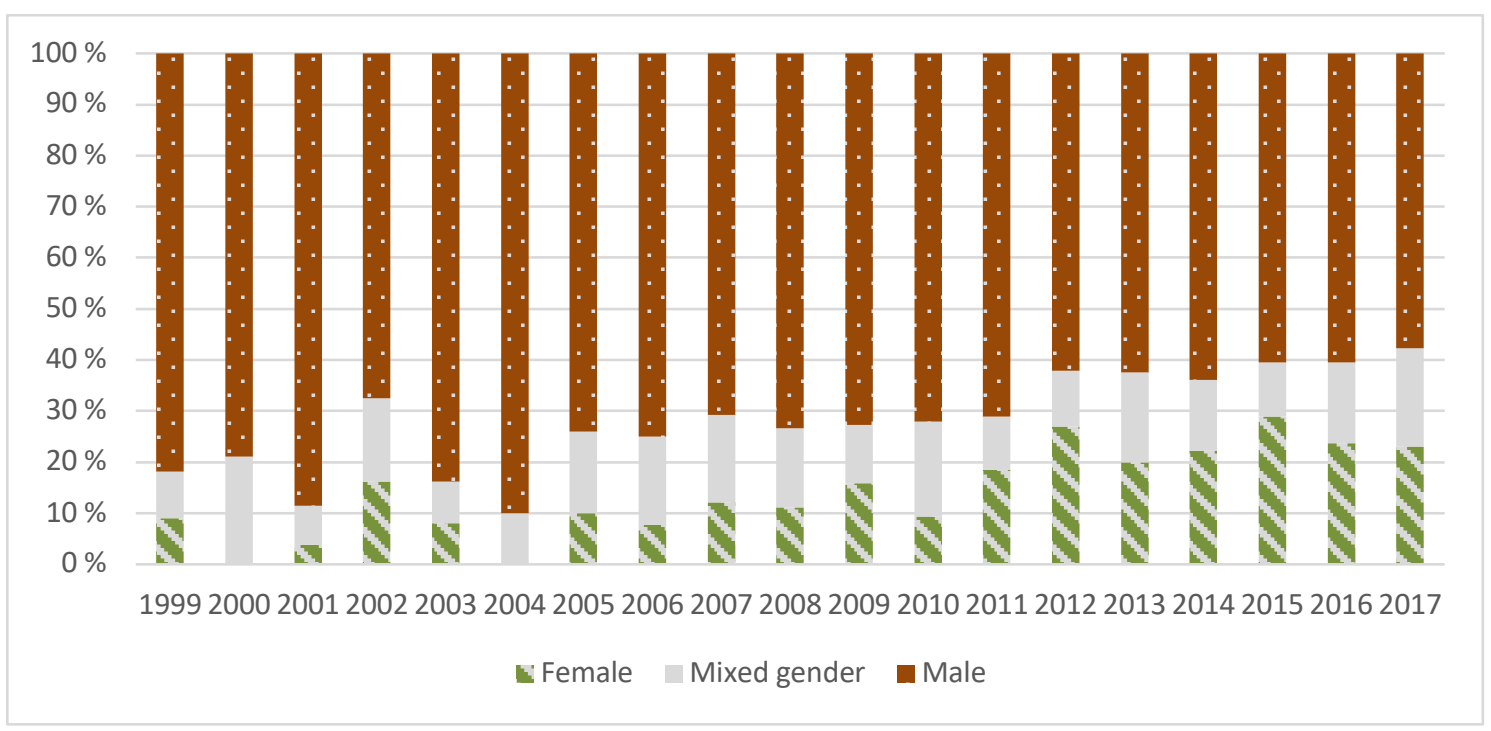

Figure 1. Gender distribution among medium-sized and headlining artists at Øya, $1999-2017 .{ }^{1}$

While 2012 appears to fall in the midst of a shift towards more gender balance, there were still only thirteen female artists out of a total of eighty-two (which also included fifty-six male and thirteen mixed-gender acts). That is, only 16 percent of the artists were female. Among festival attendees that year, on the other hand, there was an even split between women and men (51 percent and 49 percent, respectively, with an average age of thirty-two). This was also a year when user-controlled media were growing fast and gaining impact worldwide. Twitter had existed for six years (having then about 250 million users), and Spotify, for four years (having then about 20 million users). Norway (and the Nordic countries in general) has been at the forefront of using new media platforms, and 2012 was, in fact, the year when revenues from digital music consumption outpaced physical income in Norway (IFPI, 2015). The following study will therefore zoom in on that year, as it represents a formative period in the gender balance of Norway's largest festival and in the alternative mediation of different artist segments, thereby constituting a unique access point to the opportunities presented to female artists and their audiences.

\footnotetext{
${ }^{1}$ Sources: Øya festival posters. For the years 1999-2006, all artists are included, as the festival was smaller and there was no distinction among categories of artists on the posters for many of these years. For the years 2007-2017, we selected medium-sized and headliner artists, based on the size and/or colour of their names on the posters. Variation in the number of artists may also be a result of different booking policies.
} 
According to Øya's own audience survey (Comte Bureau, 2012), the musical program was people's primary reason for coming, which demonstrates the potential of an examination of user-controlled mediation of the music. Importantly, by 2012, most Øya visitors had a smartphone with online connection (90 percent, as opposed to 71 percent in 2011; ibid.). While the Norwegian population has generally included early users of social media and streaming services (Mulligan, 2012), Øya visitors were even more likely to be at the forefront of exploring the potential of these new media for musical purposes. Øya also attracts the attention of numerous editorial media, making it an especially intense site of music mediation.

Regarding mediation, we want to investigate both the discourse about artists (exposure) and the extent to which the audience listens to their music (experience). In addition, we will look at the ways in which audiences' direct experiences of music manifest in the form of evaluation in both editorial and user-controlled media. We will explore all three forms of conveyance via editorial and user-controlled media, as illustrated below (table 1). In what follows, we will first explain our selection of editorial media, then our selection of user-controlled media.

\begin{tabular}{|l|l|l|l|}
\hline & Music exposure & Music experience & Music evaluation \\
\hline Editorial media & Press coverage & Radio airplay & Reviews \\
\hline User-controlled media & Twitter commentary & Streaming & Evaluation tweets \\
\hline
\end{tabular}

Table 1. Forms of music mediation.

In terms of journalistic coverage, we wanted to focus on established editorial groups and therefore only surveyed all of the newspapers and broadcasters founded before the year 2000 (in Norway). We also investigated the online editions developed by these media houses later on. There is great variety in the editorial profiles of these media, as well as in the specific journalistic items we studied. The articles in the days before the festival, to start with, differed from the reviews in the aftermath, as these were about the live performances and were more dependent on the evaluation of the individual journalists. Taken together, however, this material can reveal overall patterns in the editorial mediation of the festival artists.

The other forms of music mediation occurred with greater frequency and generated data that was harder to obtain and assess. We therefore chose one specific 
medium within each form. In terms of music broadcasting, we chose NRK P3. NRK is the licence-funded Norwegian public service broadcaster (established in 1933), and P3 is its radio channel targeting young people (established in 1993 and commanding a market share of about 25 percent of listeners ages fifteen to twenty-nine in 2012, making it a major player in this market). As a public service broadcaster, NRK is committed to 'strengthen[ing] Norwegian language, identity and culture', and at least 35 percent of its music is supposed to be Norwegian in origin (NRK, 2015). These directives inform NRK's editorial decisions, including which artists should be included in P3's playlists, which comprise about one hundred artists and are updated each week. NRK's obligations do not explicitly address gender balance, but our investigation will reveal what P3's gender pattern is, and whether it parallels that of Øya.

In terms of user-controlled media, we chose Twitter in order to engage with how people comment on and evaluate the Øya artists. Already in 2012, Twitter was surfacing as a significant arena for semi-public discussions and was used by many people who were interested in cultural and social issues (Moe and Larsson, 2014). Importantly, users' tweets are openly available, thereby also allowing for both quantitative and qualitative analysis. In 2012, there were already 683000 Twitter users in Norway (by 2016, there were 1022 000, according to Ipsos, 2016). As an immediate and unfiltered channel for anyone who wanted to express a point of view, Twitter offered a new opportunity for the exposure of female (and male) artists.

Lastly, the user-controlled music service for this study is WiMP (called Tidal after 2014), ${ }^{2}$ which was launched in 2009 and, by 2012, was the second largest streaming service in Norway (after Spotify), with about 350000 users at that time (Maasø, 2016). WiMP offered easy and immediate access to all the artists performing at Øya, and we were given the opportunity to study WiMP's streaming data. Analysis of these data has already shown that the streaming of Øya artists increased substantially (doubled, in fact) as the festival approached, as well as in its aftermath (ibid.). This existing research also indicates the WiMP-curated Øya playlists accounted for much of the streaming before the festival, but that streaming after the festival was more based on the individual preferences of users. This insight is relevant to our interest in how the

\footnotetext{
${ }^{2}$ Aspiro, the company behind WiMP, formed a new streaming service, Tidal, in 2014. In 2015, WiMP's services were merged into Tidal. The same year, Aspiro was sold to rapper Jay-Z (Johannessen \& Tobiassen, 2017). Our data are from 2012.
} 
live performance of (female and male) artists might have impacted the preferences of music streamers.

To our knowledge, no other study has investigated editorial and user-controlled media during a live music festival, combining quantitative measures with content analysis. The case study method enables us to mix methods and create a rich data stream that is suited to inform hypotheses and also provide comparative material for later research (Yin 2012).

\subsection{Selection of artists}

As to the Øya artists, we decided to exclude small artists and focus instead on mediumsized artists and headliners, because they command a certain volume of streaming and tweeting, whereas numbers for smaller artists are susceptible to outliers-even very small changes in nominal numbers give rise to strong relative effects. We identified the headliners and medium-sized artists using the Øya festival's own categorisation, as displayed on its festival poster. ${ }^{3}$ We grouped the artists according to gender in three categories: female artists (F), male artists (M), and mixed-gender bands (M/F). Female artists such as Ane Brun were placed in the female category despite having men in the backing band. Bands with no clear lead artist, such as, for example, the Chromatics, were regarded as mixed gender. According to these criteria, then, there were twentythree male artists, ten female artists and four mixed-gender bands among the mediumsized artists and headliners at Øya in 2012. Because we wanted to focus mainly on the differences between male and female artists, mixed-gender bands were then excluded from further analysis. Artists with less than twenty Øya-related tweets were also excluded, because the low number of tweets made it difficult to identify tweeting patterns for artists. We thus ended up with sixteen male artists (A \$AP Rocky, Baroness, the Black Keys, Bon Iver, the Congos, Frank Ocean, Karpe Diem, Lars Vaular, Lightships, OFWGKTA, Refused, SBTRKT, Sondre Lerche, the Stone Roses, the War on Drugs, Yelawolf) and nine female artists (Ane Brun, Bjørk, Feist, First Aid Kit,

\footnotetext{
${ }^{3}$ Artists highlighted in red on the poster are headliners. Artists displayed via medium-sized fonts (that is, the font size of 'The War on Drugs' and 'ASAP Rocky' or bigger) were categorised as medium artists.
} 
Florence + the Machine, Jessie Ware, Siri Nilsen, St. Vincent, Susanne Sundfør). ${ }^{4}$ The fairly low number of artists made it possible to track media attention at all the chosen media platforms for all artists. At the same time, the share of medium-sized and headlining artists included in the analysis is high enough to identify valid patterns of mediation for these artist groups at the festival.

\subsection{Data collection and analysis}

\subsubsection{Exposure: Press coverage}

We searched Retriever's Atekst (https://www.retriever.no), an online archive of Norwegian and Swedish newspapers and magazines, for reviews and news stories which contained the words Øya and the name of each artist, within a limited time window from 1 July to 31 August 2012 (the festival took place 7-11 August). As mentioned, the sources we searched were limited to Norwegian newspapers and broadcasters established before 2000, as well as any affiliated online editions. We further narrowed down the results to cases which specifically mentioned the respective artists' performances at the Øya festival, leaving out cases which mentioned Øya and the artist names in separate contexts. The time period for the search matched the sevenweek window of the radio airplay data. We then sorted the results into pre-event and post-event coverage. We also looked into patterns in the relationship between the gender of the music journalists and their accounts of the performances.

As a measure of exposure, we counted how many journalistic items each artist had pre-event (the three weeks preceding the festival week) and post-event (the three weeks following the festival week), respectively. We then calculated the change from pre- to post-event exposure for each artist.

\subsubsection{Exposure: Twitter}

Data was collected via Hoot Suite (https://hootsuite.com/), a provider of social media management which can be used to collect tweets based on self-selected search words. We entered the relevant search words in Hoot Suite prior to the festival, and all tweets including words that contained Øya, øya, Oya or oya were

\footnotetext{
${ }^{4}$ OFWGKTA lacked an artist ID in the WiMP data, and the streaming data for SBTRKT included some inexplicably extreme values. Both were therefore excluded from the analysis of streaming activity.
} 
harvested. After the festival, we received text files from Hoot Suite with all of the tweets mentioning these words, including both the actual content of the tweets and the metadata accompanying them. The tweets were collected over a seven-week period, starting three weeks before the festival and ending three weeks after.

Duplicates were deleted, and the tweets were sorted according to artists/bands. The total number of tweets was 336 for female artists and 913 for male artists. We then counted the total number of Øya-related tweets, as well as the change from before to after the concert, with and without retweets, for each artist.

\subsubsection{Experience: Radio airplay}

We received playlists for weeks 29-35 from NRK P3. The radio channel uses three different playlists for regularly played music: A, B and C lists. The playlists we received covered two to three weeks at a time and sometimes overlapped by a week. We decided to concentrate on a seven-week time window surrounding the festival, using the lists for weeks 29-31, 31-32, 33-34 and 34-35. Numbers for weeks which appear in more than one playlist are collected from the most recent list. On average, approximately one hundred artists appeared on the three lists. Medium-sized and headlining Øya artists amounted to, on average, 6,69 percent $(\mathrm{SD}=0,005)$ of all artists on the lists (see figure 2).

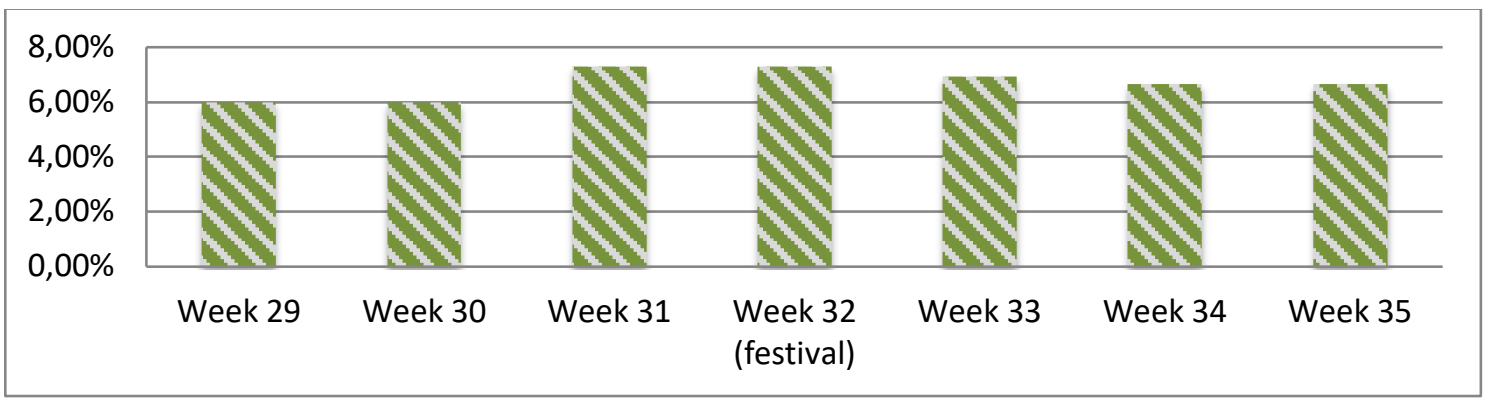

Figure 2. Medium-sized Øya artists and headliners in share of all radio airplay on NRK P3.

The quantity of songs on each list varied from week to week, along with how many times a day the songs on each list were played. For weeks 29 through 35, the A list had between six and nine songs played between six and eight times a day; the B list had about fifty songs played between three and five times a day; and the $\mathrm{C}$ list had about fifty songs played once or twice a day. In order to derive an exact number for each list, we used the centre value in each category in our calculations: a song on the A 
list had seven plays per day, a song on the B list had four plays, and a song on the $\mathrm{C}$ list had 1,5 plays. We multiplied these numbers by seven to get the number of plays per week for each artist. Artist collaborations were split between the two artists. In addition to the number of plays, we also looked at the share of plays of the total for each gender category to see how the balance between male and female artists developed over the seven weeks.

\subsubsection{Experience: Streaming}

We relied on anonymised data of the streaming of the Øya festival artists using WiMP in 2012, which was available through the Clouds and Concerts project at the University of Oslo. ${ }^{5}$ The data encompassed all of the activity by all of the users in Norway over the seven weeks surrounding the festival week, plus two control weeks in early June. (For further details regarding the initial preparation and analysis of this data, see Maasø, 2016.) For this measure, we had data per day, which meant that we could organise the data as a time series of streams per day. In order to capture the effect of Øya and exclude other events, we limited the time period to ten days before the concert day and ten days after it (for a total of twenty-one days). The time series were normalised by calculating streaming for each day as a share of the streaming on the concert day for each artist. Mean pre-event (ten days preceding the concert) and post-event (ten days following the concert) streaming figures were calculated for each artist.

\subsubsection{Evaluation: Post-event editorial reviews and share of evaluation tweets}

The measures explained so far are exclusively quantitative. Regarding post-event editorial reviews, however, we also looked at qualitative content by considering how positive or negative each review was. In those cases where the reviewer had rated the concert using numbers, we took that rating into consideration as well. We gave each review a grade from 1 to 5 , where 1 was very poor, 2 was poor, 3 was fair, 4 was good, and 5 was very good. Below are some excerpts of reviews (translated by the authors) which were considered good, fair and poor, respectively:

\footnotetext{
${ }^{5}$ See http://www.hf.uio.no/imv/english/research/projects/cloudsandconcerts/.
} 
Good review:

The sound is terribly snappy in the beginning, during the staccato-y 'Marrow', but it gets better as Clarke really gets the iron grip on a bunch of excellent songs, which get rougher treatment here than on the record. And WHAT a guitar player she is! (Enlid, 2012)

Fair review:

The visual part is uniquely ostentatious, and absolutely worthy of an arena artist. The instrumentation is eccentric but effective. [...] However, parts of the concert are over the head of most of the audience. 'Virus' and 'Hollow', which consist of a massing Björk against a backdrop of atonal organ tones, is a bit too much for most audience members. (Øyre, 2012)

Poor review:

As the band progressed through the set, it turned out to be a game of chance whether Ian Brown would start the song on the correct tone or not. Every other song was sourer than the stench from a porta potty. This affected the rest of the band, who eventually looked like they were going to perish from boredom.

(Hvidsten, 2012)

In addition, we counted the number of reviews for each artist and weighted the review grade of each artist using the following formula: average review grade $\mathrm{x}(1+$ number of reviews / 10). (Dividing the amount of reviews by ten makes the average rating remain the principal factor.) The resulting measure, called the "weighted review score," reflects both the degree of positive evaluation in each review and the total number of reviews the concert achieved.

As a measure of post-event evaluation in user-controlled media, we used the share of evaluation tweets out of all tweets, excluding retweets, for each artist (see also description above). The total number of evaluation tweets was 172 for female artists (which amounts to 51,19 percent of all tweets about female artists), and 319 for male artists (or 34,93 percent of all tweets about male artists). Some examples of evaluation tweets are given below (authors have been anonymised):

@ NN: so; whats been going on in my life lately? well, I've been to \#øyafestivalen and saw @bjork—it was soooooo amazing! \#björk 
@NN: Everything that I mentioned this morning turned out to be smashing. Except for Mirror Lakes. I was probably too drunk to enjoy snoreindie. \#øya2012 \#thisistheone 6

@NN: During@boniver at \#øya I realised that life has never been better. It was magical. No band or concert can ever beat tonight. Thank you.

\subsubsection{Measure of popularity}

As a measure of popularity, we used the total number of streams in WiMP for all nine weeks for each artist. This measure is not only experience but also reflects exposure and evaluation (Maasø 2016). Because of the large number of streams, it is also robust against outliers.

\subsubsection{Statistical analyses}

Regression analyses with gender and popularity as independent variables were conducted for all measures with (a) the total activity for the festival period for each artist and (b) the change in activity from pre- to post-concert as dependent variables. Then, a regression analysis with the same independent variables (gender and popularity) was conducted for each of the two evaluation measures - that is, weighted review score (editorial) and share of evaluation tweets (user-controlled). We conducted all statistical analyses in SPSS (version 25).

\section{Results}

In the following, we will, first, present results for total activity on the different media platforms during the seven weeks surrounding the festival period. Second, we proceed to results for the concert-related effects - that is, change in exposure and experience from pre- to post-concert and evaluation of the concert. In each section, we will present patterns for both editorial and user-controlled media. Descriptive statistics for all measures are provided in table 2. Because 'Streaming_total' was used as measure of the predictor 'Popularity', the two artists who lacked artist ID in the streaming data had to

\footnotetext{
${ }^{6}$ Translated from Norwegian by the authors.
} 
be excluded from all statistical analyses. All statistical analyses are thus conducted with $\mathrm{N}=23$.

\begin{tabular}{|c|c|c|c|c|c|}
\hline MEASURE & $\mathrm{N}$ & Minimum & Maximum & Mean & StDev \\
\hline COVERAGE_TOTAL (number of journalistic items) & 25 & 0 & 40 & 15 & 10.7 \\
\hline TWITTER_TOTAL (number of tweets) & 25 & 12 & 157 & 50 & 36.5 \\
\hline RADIO_TOTAL (number of plays) & 25 & 0 & 336 & 47 & 92.6 \\
\hline STREAMING_TOTAL (in share of mean, mean=1) & $23^{a}$ & 0.56 & 4.67 & 1 & 1.26 \\
\hline COVERAGE_CHANGE (number of journalistic items) & 25 & -9 & 17 & 0.4 & 6 \\
\hline TWITTER_CHANGE (number of tweets) & 25 & 4 & 81 & 23 & 18.5 \\
\hline RADIO_CHANGE (number of plays) & 25 & 0 & 84 & 5.6 & 18.2 \\
\hline $\begin{array}{l}\text { STREAMING_CHANGE } \\
\text { (in share of streams on concert day, concert day=1) }\end{array}$ & $23^{a}$ & -0.13 & 0.63 & 0.09 & 0.19 \\
\hline REVIEWS (weighted review score) & 25 & 0 & 9 & 5 & 2.7 \\
\hline $\begin{array}{l}\text { EVALUATION-TWEETS } \\
\text { (in share of all tweets, all tweets=1) }\end{array}$ & 25 & 0.10 & 0.60 & 0.44 & 0.13 \\
\hline
\end{tabular}

a Two artists were excluded due to a lack of artist ID in the streaming data.

Table 2. Descriptive statistics of all measures.

\subsection{Total activity on all media platforms}

\subsubsection{Exposure}

Press coverage (editorial): Male artists are on average subjected to more editorial press coverage during the festival period (see figure 6). A multiple regression analysis with gender and popularity as independent variables explains 52 percent of the variance $\left(\mathrm{R}^{2}=.52, \mathrm{~F}(2,19)=10.46, \mathrm{p}=.001\right)$. Popularity significantly predicted press coverage $(\beta=.659, \mathrm{p}=.001)$; there was also a trend towards significance for gender $(\beta=.313, \mathrm{p}=.063)$. One outlier was excluded (standardised residual > 3 StDev).

Twitter (user-controlled): Male artists are on average also subjected to more exposure on Twitter during the festival period. Looking into the tweets by the industry/artists, we see that many artists were active on Twitter. ${ }^{7}$ Overall, however, there is great variation

\footnotetext{
${ }^{7}$ These artists were particularly active on Twitter during the Øya 2012 festival period: Afghan Whigs (@theafghanwhigs), Best Coast (@BestCoast), Bon Iver (@boniver), Jessie Ware (@JessieWare), Lars Vaular (@LarsVaular),SBTRKT (@SBTRKT), Siri Nilsen (@sirinilsen),
} 
in Twitter activity among the artists, but no indication of a gendered pattern.

A multiple regression analysis with gender and popularity as independent variables explained 73 percent of the variance $\left(R^{2}=.73, F(2,20)=26.771, p<.001\right)$. Both gender $(\beta=.281, \mathrm{p}=.026)$ and popularity $(\beta=.801, \mathrm{p}<.001)$ significantly predicted Twitter exposure.

\subsubsection{Experience}

Radio airplay (editorial): Generally, there is a clear dominance of male artists in the editorial playlists on NRK P3. In all seven weeks investigated in this study, over 70 percent of the artists were male on the A, B and C lists (see figure 3 ).

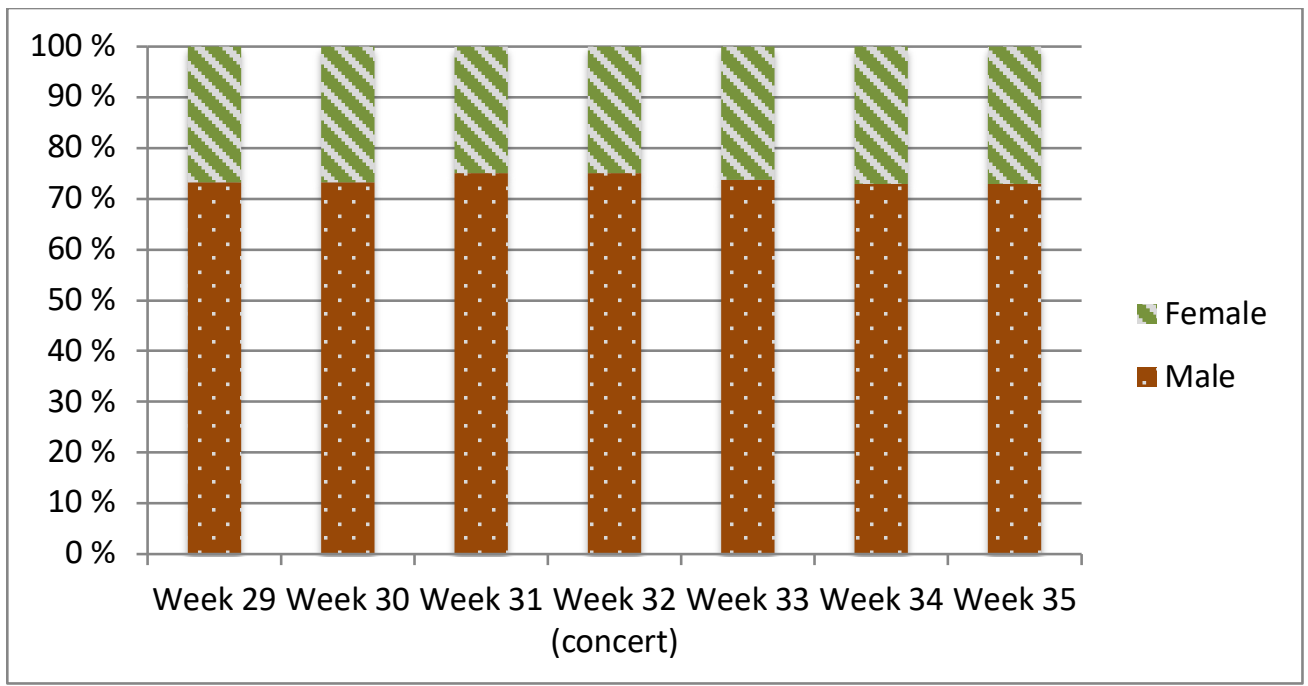

Figure 3. Distribution of male and female artists on NRK P3 playlists in weeks 29 through 35.

NRK is more balanced than Øya, however, which only featured 16 percent female artists. Furthermore, female artists amounted to 46 percent of all airplay for the Øya artists (medium-sized and headliners) in NRK P3 (see figure 4).

Sondre Lerche (@SondreLerche), St. Vincent (@st_vincent), Susanna (@SusannaMagical), Susanne Sundfør (@susannesundfor) and War on Drugs (@TheWarOnDrugs). 


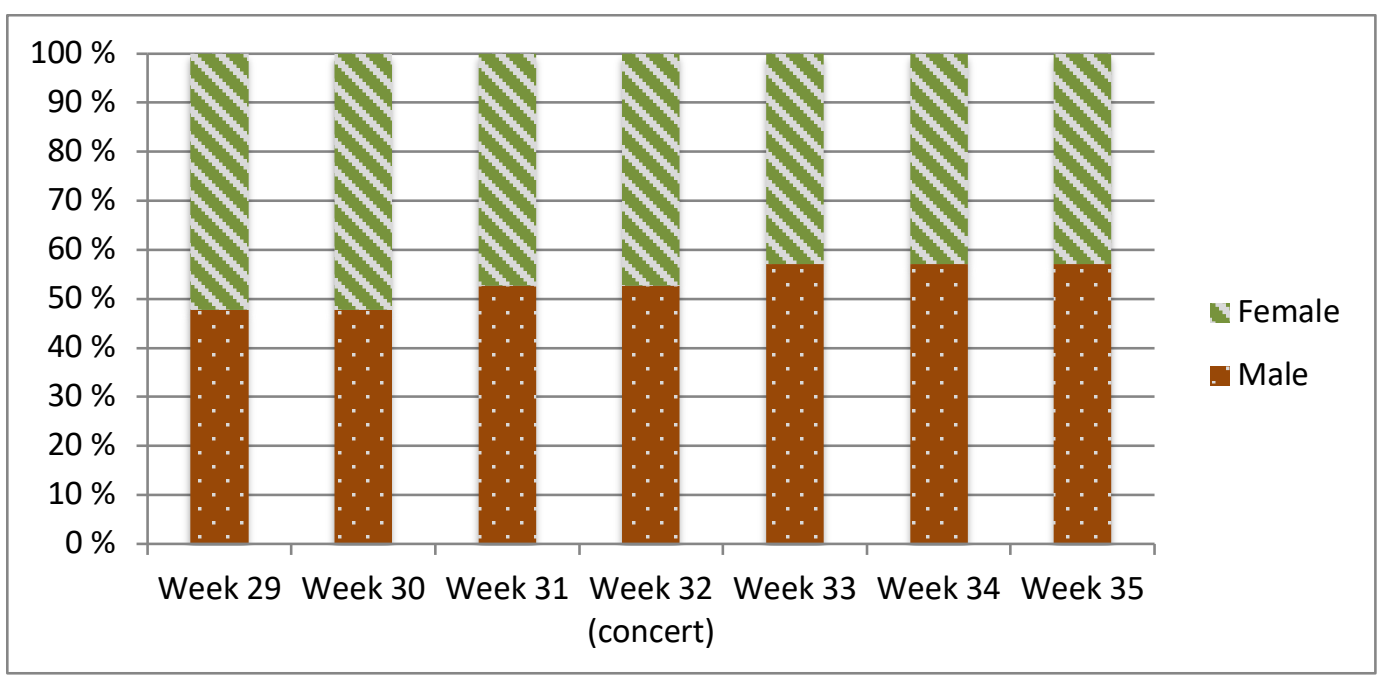

Figure 4. Distribution of airplay between male and female Øya artists in NRK P3 for weeks 29 through 35.

A multiple regression analysis with gender and popularity as independent variables explains 68 percent of the variance $\left(\mathrm{R}^{2}=.68, \mathrm{~F}(2,19)=19.99, \mathrm{p}<.001\right)$. We found that while popularity significantly predicted radio airplay $(\beta=.814, \mathrm{p}<.001)$, gender did not $(\beta=.092, \mathrm{p}=.490)$. One outlier was excluded (standardized residual $>3$ StDev).

Streaming (user-controlled): Music by all of the Øya artists was streamed by WiMP users during the festival period. Regarding the results for the streaming of medium-sized and headlining artists, we see that over the twenty-one days surrounding the festival concert as a whole, six out of ten streams were of music by male artists, and four of ten were of music by female artists. Male artists had, on average, a higher level of streaming before the festival and a higher peak in streaming on the concert day (see figure 5). However, the level of streaming after the concert was higher for female artists than for male artists when measured as a share of average streaming over the period; the female artists, then, have a higher and longer post-event 'streaming tail' (Danielsen and Kjus, 2017). 


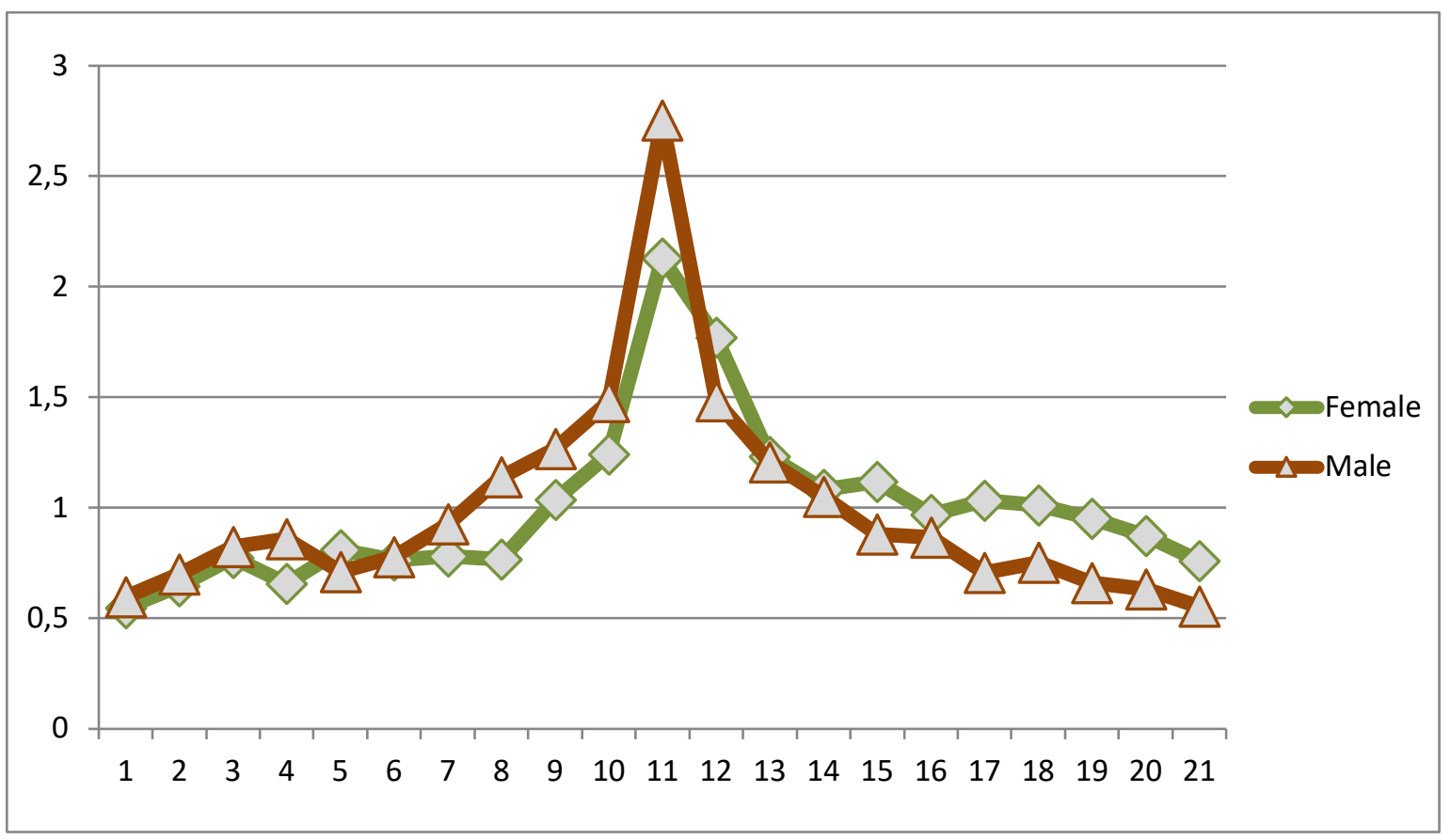

Figure 5. Time series of streaming for male and female artists, normalised by average streaming for each artist over concert day \pm 10 days (concert day $=11)$.

A multiple-regression analysis with gender and popularity as the independent variables explains 54 percent of the variance $\left(\mathrm{R}^{2}=.54, \mathrm{~F}(2,20)=11.53\right.$, $\mathrm{p}<.001$ ). It was found that popularity (that is, the total number of streams in the entire data set available) significantly predicted normalised concert-related streaming (concert day \pm 10 days normalised on concert day for each artist) $(\beta=.696, p<.001)$, whereas gender $\operatorname{did} \operatorname{not}(\beta=-.237, p=.136)$. Unsurprisingly, the correlation between popularity (total streaming) and the dependent variable (concert day \pm 10 days) is high (Pearson's $r=.69, \mathrm{p}<.001$ ).

\subsection{Concert-related effects on exposure, experience and evaluation}

An overview of the descriptive statistics for all measures of concert-related effects is provided below (figure 6). 


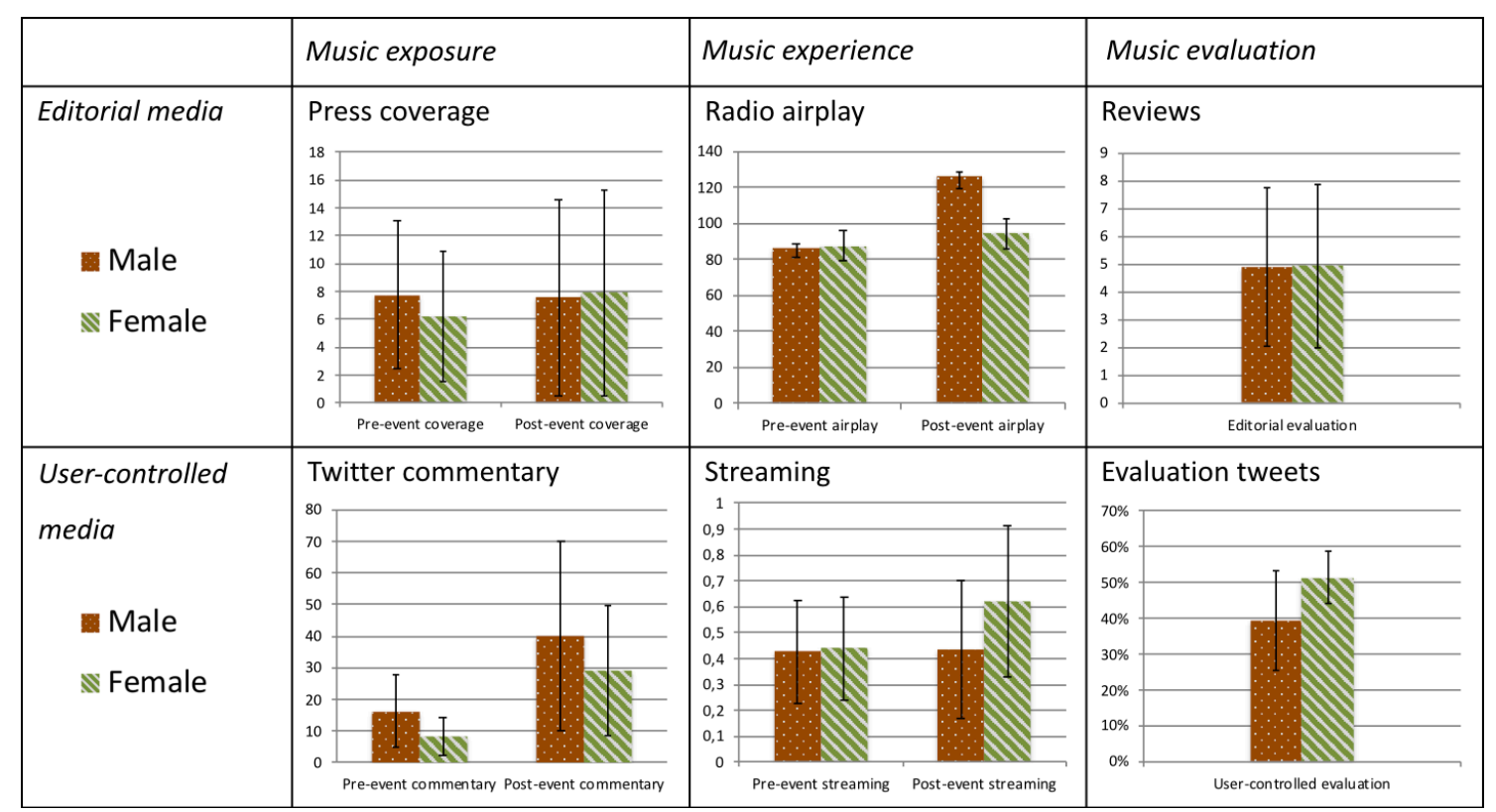

Figure 6. Overview of results for all measures: exposure, experience and evaluation for male and female artists before and after the festival concert. Press coverage $=$ number of journalistic items, Twitter $=$ number of tweets, Radio airplay $=$ number of plays, Streaming $=$ share of streaming on concert day, Reviews $=$ weighted review score, and Evaluation tweets $=$ share of tweets. Error bars $= \pm 1$ StDev.

\subsubsection{Exposure}

Press coverage: Descriptive statistics show that male artists on average are subjected to more exposure in editorial media before the event (see figure 6). The relative increase in coverage is substantial for female artists (27 percent on average) but absent for men (-3 percent). There is, however, great variability in the data $(\min =0, \max =14$ for pre-event coverage, and $\min =1, \max =26$ for postevent coverage).

A multiple regression analysis with gender and popularity as independent variables yielded no significant results and explained only 7 percent of the variance $\left(\mathrm{R}^{2}=.07, \mathrm{~F}(2,20)=.754, \mathrm{p}=.484\right)$. Neither of the two predictors was significant (gender, $\beta=.143, p=.515$; popularity, $\beta=.225, p=.309$ ).

Twitter: As to exposure in user-controlled media measured as the total of festivalrelated tweets without retweets, the descriptive statistics indicate a pattern similar to that of the editorial media. Female artists generally have fewer tweets, but their relative 
increase is higher (see figure 6). The increase in commentary from pre- to post-event is substantial for both artist segments compared to editorial media. ${ }^{8}$

Multiple regression analysis was used to test whether gender and popularity predict this change in Twitter commentary from pre- to post-event. The results show that the model explains 55 percent of the variance $\left(\mathrm{R}^{2}=.55, \mathrm{~F}(2,20)=12.261, \mathrm{p}<.001\right)$. We found that popularity significantly predicted a change in Twitter commentary $(\beta=.734$, $\mathrm{p}<.001)$, whereas gender did not $(\beta=.097, \mathrm{p}=.524)$.

\subsubsection{Experience}

Radio airplay: The descriptive statistics show that there is an increase in airplay for Øya artists over the seven weeks surrounding the festival (figure 7). This partly reflects a general increase in the total number of songs on the radio playlists during this period. The distribution seems to develop gradually in favour of male artists, especially in the weeks following the festival.

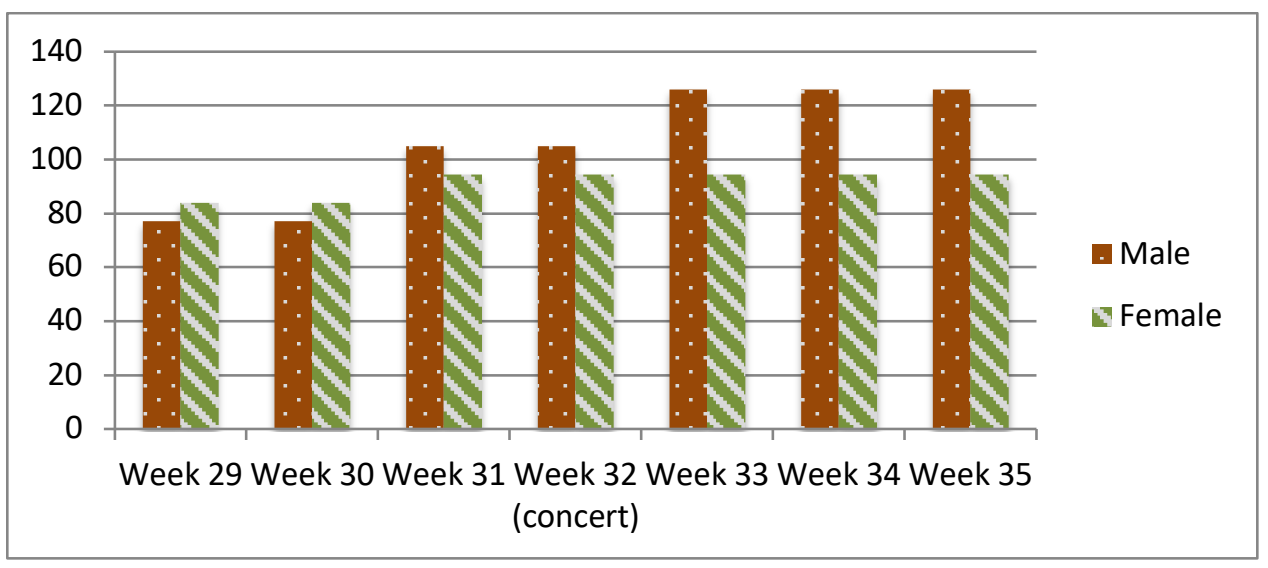

Figure 7. Total number of plays for male and female Øya artists in NRK P3 for weeks 29 through 35.

Looking further into the numbers for medium-sized and headlining Øya artists, we see that two female artists were listed in weeks 29-30, then three in weeks 31-35. The number of male artists on the lists (five) was stable throughout the whole period. In general, there were fewer female artists on the lists, but their average rotation was higher than that of the male artists. However, this difference decreased in the weeks

\footnotetext{
${ }^{8}$ If we include retweets, the figures look about the same. Male artists have more tweets both before and after the event, but again the relative increase is higher for female artists (262 percent on average, compared to 208 percent for male artists).
} 
following the festival (the rotation of male artists increased, whereas the rotation for female artists stayed the same). Ultimately, the aggregate numbers for all male Øya artists were slightly higher than those for female artists, and this discrepancy increased in the weeks following the festival.

No statistical tests were conducted on this material, as there was a change in radio airplay for only three of the artists in our study.

Streaming: We see an increase in streaming from pre- to post-event for female artists measured in share of streaming on concert day $(\mathrm{M}=0.18, \mathrm{SD}=0.23)$, but almost no difference in streaming for male artists $(\mathrm{M}=0.02, \mathrm{SD}=0.12)$.

Multiple regression analysis was used to test whether gender and popularity predict change in streaming from pre- to post-event. The results show a trend towards significance, which indicates that the model explains 24 percent of the variance $\left(\mathrm{R}^{2}=.238, \mathrm{~F}(2,20)=3.12, \mathrm{p}=.066\right)$. We found that gender significantly predicted a change in streaming $(\beta=-.438, p=.036)$, whereas popularity $\operatorname{did} \operatorname{not}(\beta=.221, \mathrm{p}=.271)$.

\subsubsection{Experience as exposure: evaluation of the concert}

Reviews: In total, the headlining and medium-sized Øya 2012 artists generated fifty-eight reviews in editorial media. With regard to gender distribution among the reviewers, we see a clear majority of male reviewers (76 percent).

Interestingly, the share of female reviewers is higher for male artists (ten out of thirty-five reviews, or 29 percent) than for female artists (four out of twenty-three reviews, or 17 percent). This also means that male reviewers account for 71 percent (twenty-five out of thirty-five) of the reviews of male artists, and 83 percent (nineteen out of twenty-three) of the reviews of female artists.

When looking into the differences in the evaluation of the concert between the two groups (see figure 6) in editorial media, we see little difference between male and female artists. Multiple regression analysis was used to test whether gender and popularity predict evaluation in editorial media, but it yielded no significant result. The model explains only 4 percent of the variance $\left(\mathrm{R}^{2}=.04, \mathrm{~F}(2,20)=.361, \mathrm{p}=.701\right)$, and neither of the predictors was significant (gender $\beta=.154, p=.491$; popularity $\beta=.103$, $\mathrm{p}=.644)$. 
Twitter: Regarding evaluation in social media, evaluation tweets represent on average a larger share of the total number of tweets for female artists $(\mathrm{M}=51$ percent, $\mathrm{SD}=7)$ than for male artists $(\mathrm{M}=39$ percent, $\mathrm{SD}=14)$. Multiple regression analysis was used to test whether gender and popularity predict the share of evaluation tweets. The results show that this model explains 31 percent of the variance $\left(\mathrm{R}^{2}=.31, \mathrm{~F}(2,20)=4.44, \mathrm{p}=.025\right)$. We found that gender significantly predicted the share of evaluation tweets $(\beta=-.475, \mathrm{p}=.019)$, whereas popularity did not $(\beta=-.278, p=.150)$. We did not have access to information on the gender of the people writing evaluation tweets.

An overview of all regression analyses is provided in table 3.

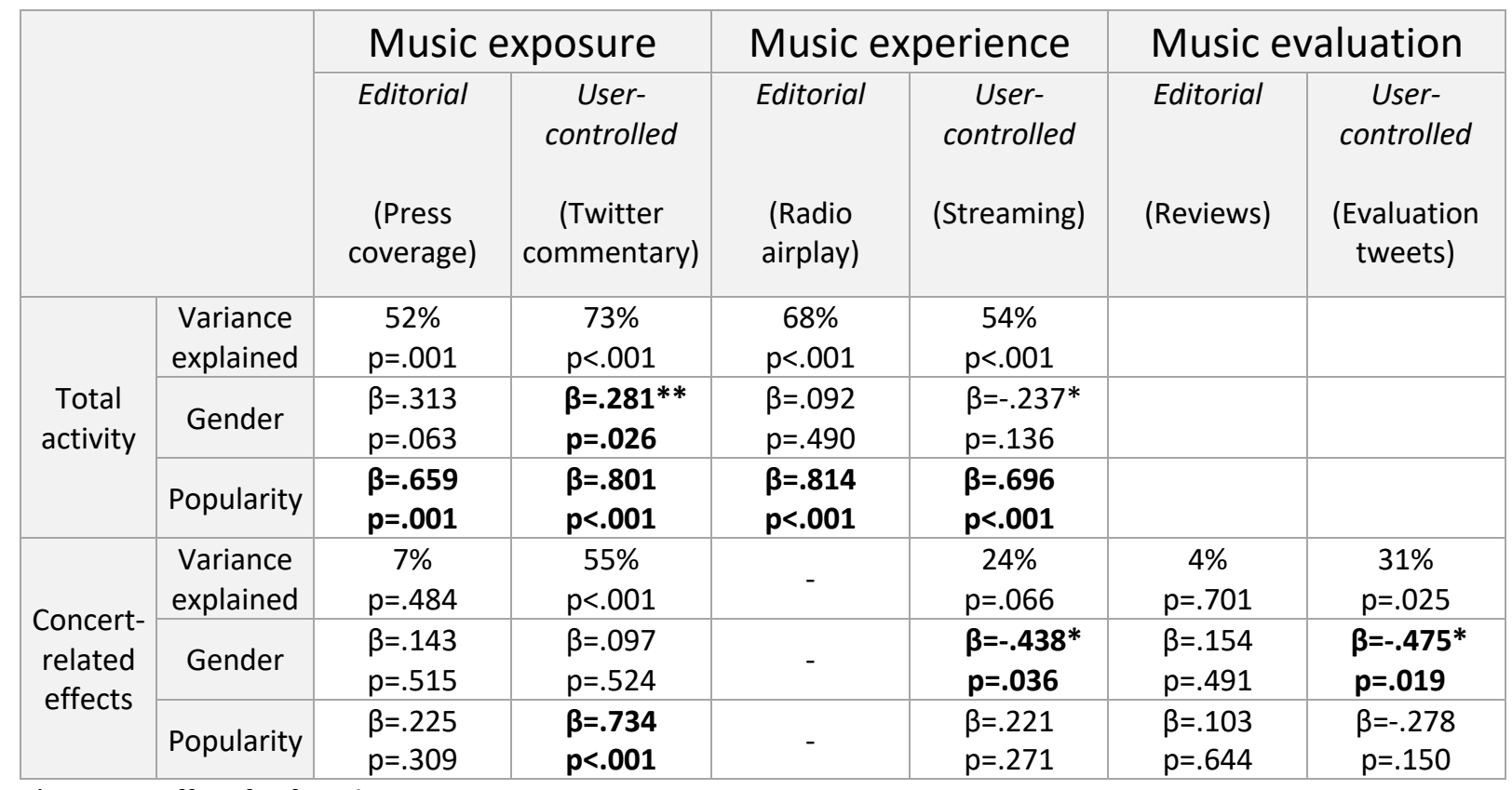

*positive effect for female artists

**negative effect for female artists

Table 3. Overview of regression analyses. Predictors: gender and popularity. Dependent variables: total activity and event-related change in exposure, experience and evaluation on editorial and user-controlled media platforms.

\section{Discussion}

The aim of the present study was to investigate the effect of a festival on music 
mediation, focusing in particular on possible differences between male and female artists. We looked closely at four different media, two of which were user-controlled and two of which were under editorial control, and we found clear patterns, both expected and unexpected, which we will discuss in what follows.

\subsection{Popularity predicts total exposure and experience}

As expected, popularity predicts festival-related attention on all media platforms. If we look at each media platform separately over the festival period as a whole (and do not distinguish between pre- and post-event), gender is found to predict attention only on Twitter. Here, female artists receive less attention than male artists, indicating that this vernacular and unchecked medium is inclined to reflect the overall gender bias of the Øya festival. It may also be viewed as a replication of the general patterns from traditional media, which tend to make men more visible (Berkers et al., 2016). Somewhat surprisingly, however, we did not find such a gender bias in the press coverage in our material, which raises doubts regarding often assumed links between male dominance in the staff and male dominance in output. One possible explanation is that Øya, which by 2012 was the country's largest festival, had become a key reference in the public debate on gender imbalance in the music sector (see, for example, Ramstad, 2010). This might also have coloured the way in which the press reviewed the festival performances. In terms of the public service broadcaster NRK P3, which claims a progressive profile in terms of both its share of Norwegian music and its promotion of music by female artists (Ofstad, 2013), we even find a clear over-representation of female Øya artists. While Øya's festival program included only 16 percent female artists, approximately 50 percent of the Øya artists which were aired via NRK's playlists were female (see figure 7).

\subsection{Event-related increase in user-controlled media}

When looking into effects of the concert on activity on the different media platforms by comparing activity pre- and post-event, we found that the festival concerts clearly increased activity on the user-controlled media platforms. This is in accordance with previous research, which also found a festival-related increase in streaming and attention in social media, or the so-called festival effect (Maasø, 2016; Danielsen and Kjus, 2017). 
In editorial media, on the other hand, there is little difference between pre- and postevent levels of activity. One possible factor here might be that editorial media have a more distant relation to the actual festival concert. The influence of the festival on radio playlists, for example, is first and foremost based on the festival program and therefore takes place before the actual concerts have happened. The streaming of festival artists, on the other hand, is closely related to the actual experience at the festival, as is demonstrated by the spike in streaming of festival artists on the given concert days (Maasø, 2016; Danielsen and Kjus, 2017). Relatedly, the increase from pre- to postevent streaming is considerable.

\subsection{User-controlled platforms favourable for female artists post-concert}

Breaking down the numbers related to change on the two user-controlled media platforms along gender lines, we see that there is an increase in attention from pre- to post-event for female artists. Regarding streaming, the event-related change is considerable. Measured in share of streaming on the concert day, female artists on average have a significantly higher level of streaming after the concert compared to their male colleagues, also when controlling for popularity. Interestingly, we know from previous research that streaming becomes even more user-controlled post-event, because playlist use shifts from editorial lists made by WiMP before the event to usercontrolled lists made after it (Maasø, 2016).

We also see an indirect positive event-related effect for female artists on Twitter: when we looked at the numbers for total activity, we found a significant gender bias favouring male artists. This bias is, however, no longer significant in the results for event-related increase in Twitter attention.

Regarding evaluation, we found that popularity does not predict evaluation on either editorial or user-controlled platforms. This is somewhat surprising but can reflect the tendency among reviewers and gatekeepers, particularly of festivals with a measure of cultural credibility, to direct their attention towards discovering promising new acts. Furthermore, we found no apparent difference in the editorial evaluation of male and female artists between male and female reviewers. This can be attributed to the ways in which women who seek positions in male-dominated groups are expected to adhere to the established ways of doing things. The gender of the artist did not predict evaluation (weighted review scores) in editorial media, as we have seen. User-controlled evaluation was, on the other hand, highly favourable for female artists. 
Both streaming and Twitter point back to the direct meeting with the audience as being particularly positive for female artists, as it works in the direction of neutralising traditional gendered media patterns. One explanation for the positive response in usercontrolled media after the concert for female artists is that the gatekeeper function of traditional media is absent (Hesmondhalgh, 2013; Lindberg et al., 2005), and that usercontrolled media invite spontaneous expression. A related explanation is that festival performances are more difficult for female artists to secure in the first place, as is indicated by the literature demonstrating the general dominance of male intermediaries in the music business (Rashaun, 2004; Schmutz, 2009; Kjus, 2016). This reality is also reflected in the generally skewed distribution in favour of male artists at the Øya festival (again, only 16 percent female artists). Given that the prospects of female artists for making it onto the festival poster are poorer than those for male artists at the same career stage, one could assume that those who do make it to the festival poster are more accomplished artists and/or better prepared to use the occasion to deliver a high-quality performance.

A complementary explanation is that the increase in user-controlled media activity for female artists after the festival concert is related to the fact that the Øya audience is half women and half men. In the case of literature, it is assumed that female authors appeal particularly to women, who are overrepresented among the reading audience (Verboord, 2011: 447), but it remains a task for future research to document whether women actually prefer the concerts and records of female artists. Yet another factor in explaining the positive effect of the concert for female artists is that the audience's direct meeting with the artists and their music undermines stereotypical notions about female artists and female-based bands. Summing up, the medium which was most influenced by cultural-political constraints was most favourable to the female artists overall, whereas user-controlled media, such as tweeting and streaming, were most favourable to the female festival artists after the festival concert.

\section{Conclusion}

This study documents the different roles of editorial and social media in artist exposure in general, and exposure in relation to live music performances in particular. It also addresses the role of various media in bringing the personal experiences of music events into the public discourse surrounding such events, mediating between music and speech about music (Feld, 1984). 
The results show that it is still a challenge for female artists to attract media attention and reach their audiences via traditional editorial media, which can be linked to the male-dominated gatekeeper function of these channels. The rise of new digital media controlled by artists and fans themselves both confirms and denies this pattern. Festival tweets in the user-controlled service Twitter were generally about male artists and thus seemed to reinforce old gender patterns. Nevertheless, user-controlled media such as streaming and tweeting also represented novel opportunities for fan contact, because audiences could use these channels to air their direct responses to the festival experience without intermediary control. The following tweets from festival attendees are examples of such responses to two of the female artists and show how new fans might be recruited as a result of the direct experience with the artists and their performance at the festival:

@NN: Something surprising always shows up on festivals, Susanna was pretty good and someone I haven't heard before. \#øyafestivalen ${ }^{9}$

@NN: @Jessie_Ware at \#øyafestivalen=amaze\&suede, i"m a fan now

These affordances of new media seem to be particularly favourable to female artists, who were given much more attention in terms of concert evaluation on Twitter after the festival concert. Overall, then, the gendered aspects of usercontrolled media differ in important ways from the picture conveyed by more established media channels and the music industry.

The two axes of investigation which underpin the design of the present studythat is, user-controlled and editorial channels for music experience, as well as exposure and evaluation in user-controlled and editorial media-represent a new approach to research into music and media. This approach provides a broad outlook on the mechanisms of mediation at work in the field of music as a whole. New insight into the favourable effect of the live experience of artists on the exposure of female artists in the media, for example, emerged exactly at the intersection of these two axes. The flipside

\footnotetext{
${ }^{9}$ Translated from Norwegian by the authors.
} 
of the richness produced by using multiple data sources, however, is that certain tendencies in the material cannot be explored in depth. It would be interesting to probe, for example, whether the gender of the reviewer matters with regard to the angle and content of festival concert reviews. Also, some important findings from our quantitative analyses cry out for qualitative investigations which were not possible within the constraints of the present study. The relationship between experience and exposure, for example, is complex and raises several questions regarding the relationship between live experience and mediated discourse: What in the experience makes an audience share it with others, and when in the process is this most likely to happen? More research is needed to understand how music experience transforms into speech about music, as well as the role of music, media and gender in this process.

Finally, it should be noted that the present work is an original case study carried out at a certain time and place in history, and that the behaviour of the artists, audiences and intermediaries selected might be coloured by context in ways which are challenging to account for in full. Hopefully, uncertainty regarding generalizability will encourage new studies elsewhere, furthering the examination of gender bias in the digital environment.

\section{Acknowledgements}

We are grateful to Per Ole Hagen, NRK P3's head of music, Mats Borch Bugge, and Tor Eide, NRK Analytics for providing access to this information. This work was supported by the Research Council of Norway [grant number 205265].

\section{References}

Baym, N. (2011). The Swedish Model: Balancing Markets and Gifts in the Music Industry. Popular Communication, 9(1), 22-38.

Bennett, L. (2014). Texting and Tweeting at Live Music Concerts: Flow, Fandom and Connecting with Other Audiences through Mobile Phone Technology. In K. Burland \& S. Pitts (Eds.), Coughing and Clapping: Investigating Audience Experience (pp. 89-100). Farnham, Surrey; Burlington, VT: Ashgate. 
Berkers, P., Verboord, M. \& Weij, F. (2016). 'THESE CRITICS (STILL) DON'T WRITE ENOUGH ABOUT WOMEN ARTISTS': Gender Inequality in the Newspaper Coverage of Arts and Culture in France, Germany, the Netherlands, and the United States, 1955-2005. Gender and Society, 30(3), 515-39.

Comte Bureau. (2012). Øya Audience Survey: Report for the Øya Festival. Comte Bureau.

Cottle, S. (2006). Mediatized Conflict: Developments in Media and Conflict Studies. Maidenhead, England: Open University Press.

Danielsen, A. (2006). Presence and Pleasure. The Funk Grooves of James Brown and Parliament. Hanover, N.H.: Wesleyan University Press.

Danielsen, A., \& Kjus, Y. (2017). The Mediated Festival: Live Concerts as Triggers of Music Streaming and Social Media Engagement. Convergence: The International Journal of Research into New Media Technologies.

Enlid, V. (2012, August 10). Skuff og popfrelse [Disappointment and pop salvation]. Adresseavisen. Retrieved from http://www.adressa.no/kultur/article3278431.ece.

Feld, S. (1984). Communication, Music, and Speech about Music. In C. Keil \& S. Feld, Music Grooves (pp. 77-95). Chicago: University of Chicago Press.

Fonarow, W. (2006). Empire of Dirt: The Aesthetics and Rituals of British Indie Music. Middletown, Conn.: Wesleyan University Press.

Frith, S. (1983). Sound Effects: Youth, Leisure and the Politics of Rock'n'Roll. London: Constable.

Hagen, A. N. (2015). Using Music Streaming Services: Practices, Experiences and the Lifeworld of Musicking (doctoral dissertation). Retrieved from https://www.hf.uio.no/imv/forskning/prosjekter/skyogscene/publikasjoner/hagen 2015.pdf.

Hesmondhalgh, D. (2013). Why Music Matters. Chichester, West Sussex, UK: Wiley and Sons Ltd.

Hvidsten, S. (2012, August 9). Sang surere enn stanken av en festivaldo [Sang sourer than the stench from a porta potty]. Dagbladet. Retrieved from https://www.dagbladet.no/kultur/sang-surere-enn-stanken-av-enfestivaldo/63284225.

IFPI. Det norske musikkmarkedet 2014 [The Norwegian music market 2014]. IFPI Norge, 2015, http://www.ifpi.no/item/79-det-norske-musikkmarkedet-2014. Ipsos. (2016). Ipsos' tracker om sosiale medier [Ipsos tracker on social media].

Retrieved from http://ipsos-mmi.no/some-tracker. 
Johannessen, S. Ø., \& Tobiassen, M. (2017, 21 January). BigBang-frontfigur: 'Komisk optimistiske prosjekter er en tradisjon i musikkbransjen' [BigBang frontman: 'Comically optimistic projects are a tradition in the music business]. Dagens Noeringsliv. Retrieved from https://www.dn.no/etterBors/2017/01/21/1406/Musikk/bigbang-frontfigurkomisk-optimistiske-prosjekter-er-en-tradisjon-i-musikkbransjen

Jones, S. (2002). Music That Moves: Popular Music, Distribution and Network Technologies. Cultural Studies, 16(2), 213-32.

Kjus, Y. (2016). Musical Exploration via Streaming Services: The Norwegian Experience. Popular Communication: The International Journal of Media and Culture, 14(3), 127-36.

Kjus, Y., \& Danielsen, A. (2014). Live Islands in the Seas of Recordings: The Music Experience of Visitors at the Øya Festival. Popular Music and Society, $37(5), 660-79$.

Kristensen, N. N., From, U. \& Kammer, A. (2017). The Changing Logics of Danish Cultural Journalism. In N. N. Kristensen \& K. Riegert (eds.), Cultural Journalism in the Nordic Countries (pp. 29-48). Gothenburg: Nordicom.

Larsson, A. O., \& Moe, H. (2014). Triumph of the Underdogs? Comparing Twitter Use by Political Actors during Two Norwegian Election Campaigns. SAGE Open, $4(4), 291-314$.

Leonard, M. (2007). Gender in the Music Industry: Rock, Discourse and Girl Power. Burlington, VT: Ashgate.

Lindberg, U., Gudmundsson, G., Michelsen, M. \& Weisethaunet, H. (2005). Rock Criticism from the Beginning: Amusers, Bruisers and Cool-Headed Cruisers. New York: Peter Lang.

Lüders, M. (2007). Being in Mediated Spaces: An Enquiry into Personal Media Practices (doctoral dissertation). Retrieved from https://www.academia.edu/406070/Being_In_Mediated_Spaces_An_Enquiry_In to_Personal_Media_Practices.

Mjøs, O. J. (2012). Music, Social Media and Global Mobility: MySpace, Facebook, YouTube. New York: Routledge.

Maasø, A. (2016). Music Streaming, Festivals, and the Eventization of Music. Popular Music and Society. Retrieved from http://dx.doi.org/10.1080/03007766.2016.1231001. 
McLeod, K. (2012). Between Rock and a Hard Place: Gender and Rock Criticism. In S. Jones, Pop Music and the Press (pp. 93-113). Philadelphia: Temple University Press.

Mulligan, M. (2012). Streaming Goes Global: Analysing Global Streaming Music Adoption. Music Industry Blog. Retrieved from https://musicindustryblog.files.wordpress.com/2011/11/streaming-goesglobal4.pdf.

NRK. (2015). NRK-plakaten [NRK's public service obligations]. Retrieved from https://www.nrk.no/informasjon/nrk-plakaten-1.12253428.

Ofstad, A. W. (2013). Musikk og allmennkringkasting: En kvantitativ studie av NRK P3s spillelister og deres utvikling [Music and public service broadcasting: a quantitative study of NRK P3s playlists and their development]. (master's thesis). Retrieved from http://bora.uib.no/handle/1956/7612.

Ramstad, E. (2010, 1 July). Hvor er jentene [Where are the girls?]. NRK. Retrieved from http://arkiv.nrk.no/lydverket/hvor-er-jentene/

Rashaun, H. (2004). Female Mix DJs: A Rarity at Radio. Billboard, 116(27), 22.

Reddington, H. (2007). The Lost Women of Rock: Female Musicians in the Punk Era. London: Ashgate.

Ricoeur, P. (1973). The Hermeneutical Function of Distanciation. Philosophy Today, $17,129-43$.

Ridgeway, C. (2011). Framed by Gender: How Gender Inequality Persists in the Modern World. New York: Oxford University Press.

Robinson, R. (2015). Music Festivals and the Politics of Participation. London: Ashgate.

Schmutz, V. (2009). Social and Symbolic Boundaries in Newspaper Coverage of Music, 1955-2005: Gender and Genre in the US, France, Germany, and the Netherlands. Poetics, 37(4), 298-314.

Tjora, A. H. (2013). Festival! Mellom Rølp, Kultur og Naring [Festival! Between trash, culture and business]. Oslo: Cappelen Damm Akademisk.

Tobiassen, M., \& Sæter, K. (2018, 9 May). Strømmekuppet [The streaming heist]. Dagens Noeringsliv. Retrieved from https://www.dn.no/staticprojects/special/2018/05/09/0600/dokumentar/stromme kuppet/?

Tschmuck, P., Pearce, P. L., \& Campbell, S. (2013). Music Business and the Experience Economy: The Australasian Case. Berlin: Springer Berlin. 
Verboord, M. (2011). Cultural Products Go Online: Comparing the Internet and Print Data on Distributions of Gender, Genre and Commercial Success.

Communications, 36(4), 441-62.

Verboord, M. (2014). The Impact of Peer-Produced Criticism on Cultural Evaluation: A Multilevel Analysis of Discourse Employment in Online and Offline Film Reviews. New Media and Society, 16(2), 921-940.

Wisløff, A. H. (2014). Røsk opp i gubbeveldet [Uproot the male domination]. Klassekampen. Retrieved from http://www.klassekampen.no/article/20140623/ARTICLE/140629982.

Øyre, T. (2012, August 10). Ingen hit-parade på Øya [No hit parade at Øya]. Dagbladet. Retrieved from https://www.dagbladet.no/kultur/ingen-hit-parade-paoya/63284932.

Yin, R. (2012). Application of Case Study Research. Third Edition. Thousand Oaks, CA.: Sage. 